М.А. Стукова ${ }^{1}$, Н.В. Заболотных ${ }^{2}$, Т.И. Виноградова ${ }^{2}$, В.Я. Гергерт ${ }^{3}$, А.С. Апт ${ }^{3}$, А.С. Капрельянц ${ }^{4}$, В.В. Ерохин ${ }^{3}$, П.К. Яблонский ${ }^{2,5}$, О.И. Киселев ${ }^{1}$

\author{
${ }^{1}$ Научно-исследовательский институт гриппа МЗ РФ, Санкт-Петербург, Российская Федерация \\ ${ }^{2}$ Санкт-Петербургский научно-исследовательский институт фтизиопульмонологии МЗ РФ, Российская Федерация \\ ${ }^{3}$ Центральный научно-исследовательский институт туберкулеза РАМН, Москва, Российская Федерация \\ ${ }^{4}$ Научно-исследовательский институт биохимии им. А.Н. Баха РАН, Москва, Российская Федерация \\ ${ }^{5}$ Санкт-Петербургский государственный университет, Российская Федерация

\section{Профилактика туберкулеза: современные подходы} \\ к разработке противотуберкулезных вакцин
}

\begin{abstract}
В обзоре освещены современные достижения в области разработки новых вакцин для профилактики туберкулеза. Представлены основные причины недостаточной эффективности вакцины БЦЖ в различных популяциях и географических регионах. На конкретных примерах рассмотрены направления дизайна новых вакцин на основе живых модифицированных штаммов Мусоbacterium bovis БЦЖ, аттенуированных штаммов Mycobacterium tuberculosis, рекомбинантных белков и вирусных векторов. Обсуждается перспектива применения схемы гетерологичной «prime-boost» вакцинации против туберкулеза.
\end{abstract}

Ключевые слова: туберкулез, М. tuberculosis, БЦЖ, вакцины, клинические исследования.

Эффективная вакцинация, направленная на предупреждение формирования «открытых» форм туберкулеза, является важнейшим фактором, ограничивающим распространение инфекции. Единственная используемая на протяжении многих десятилетий вакцина БЦЖ во многом перестала удовлетворять требованиям практического здравоохранения. Необходимо отметить, что развитие туберкулеза на сегодняшний день отмечается не только у некачественно привитых или непривитых детей, но и у эффективно БЦЖ-вакцинированных лиц [1]. По-прежнему серьезной проблемой, имеющей тенденцию к нарастанию, остаются поствакцинальные осложнения [2].
Принципиальным недостатком вакцины БЦЖ, которая представляет собой живой аттенуированный штамм Mycobacterium bovis BCG, является постепенное (в течение 3-7 лет) снижение напряженности поствакцинального иммунитета [3, 4]. Согласно результатам контролируемых исследований, это приводит к практически полному отсутствию защитного эффекта уже через 10 лет после вакцинации [5]. В то же время использование БЦЖ для ревакцинации, направленной на поддержание противотуберкулезного иммунитета, по данным экспертов Всемирной организации здравоохранениия, признается неэффективным [6], и это подтверждают

M.A. Stukova ${ }^{1}$, N.V. Zabolotnyh ${ }^{2}$, T.I. Vinogradova ${ }^{2}$, V.Ia. Gergert ${ }^{3}$, A.S. Apt $^{3}$, A.S. Kaprelyants ${ }^{4}$, V.V. Erokhin ${ }^{3}$, P.K. Yablonsky ${ }^{2,5}$, O.I. Kiselev ${ }^{1}$

${ }^{1}$ Research Institute of Influenza, Ministry of Health and Social Development, Saint Petersburg, Russian Federation

${ }^{2}$ Saint-Petersburg Research Institute of Phthisiopulmonology, Ministry of Health and Social Development Saint Petersburg, Russian Federation

${ }^{3}$ Central Institute for Tuberculosis, Russian Academy of Medical Science, Moscow, Russian Federation

${ }^{4}$ A.N. Bach Institute of Biochemistry, Russian Academy of Sciences, Moscow, Russian Federation

${ }^{5}$ Saint Petersburg State University, Russian Federation

\title{
Prevention of tuberculosis: current approaches to development of vaccines
}

This review is focused on recent advances in development of new vaccines for the prevention of tuberculosis. The main reasons for lack of $B C G \mathrm{vaccine}$ efficacy in different populations and geographic regions are presented. Design of new vaccines based on live modified strains of Mycobacterium bovis $B C G$, attenuated strains of Mycobacterium tuberculosis, recombinant proteins and viral vectors is considered in the specific examples. The usage of the heterologous «prime-boost» vaccination strategy against tuberculosis is discussed.

Key words: tuberculosis; M. tuberculosis, BCG, vaccines, clinical trials. 
результаты рандомизированного исследования, проведенного в Бразилии с участием более 300000 школьников в возрасте от 7 до 14 лет [7].

\section{Причины недостаточной эффективности вакцины БЦЩ}

По мнению авторов, занимающихся вопросами противотуберкулезной вакцинации, эффективность вакцины БЦЖ зависит от ряда факторов, среди которых можно отметить следующие:

- влияние микобактерий окружающей среды на развитие адекватного поствакцинального иммунного ответа;

- несостоятельность вакцины при исходной поляризации иммунного ответа в сторону $\mathrm{T}_{\mathrm{x} 2}$-звена;

- отсутствие в штамме M. bovis БЦЖ ряда важнейших антигенов;

- неспособность вакцины обеспечивать оптимальный баланс CD4+ и CD8+ T-клеточных звеньев иммунитета;

- отсутствие выработки долгоживущих «центральных» Т-клеток памяти;

- имеющиеся различия между вакцинными штаммами БЦЖ, используемыми для производства вакцины.

На формирование полноценного поствакциналь-

ного иммунитета значительное влияние могут оказывать микобактерии окружающей среды $[8,9]$. Согласно одной из гипотез (гипотеза маскирования), вакцинация БЦЖ не способна существенно изменить иммунный ответ организма, сенсибилизированного микобактериями окружающей среды. Другая точка зрения (гипотеза блокирования) заключается в том, что сформировавшийся под влиянием микобактерий окружающей среды иммунитет ограничивает персистенцию вакцинного штамма БЦЖ в организме привитого, препятствуя формированию полноценной противотуберкулезной защиты [10]. Этим объясняется хороший защитный эффект вакцины БЦЖ у иммунологически «наивных» новорожденных и его отсутствие у взрослых лиц, подвергшихся воздействию микобактерий.

При разработке новых вакцин, исходя из первой гипотезы, защиту сенсибилизированных лиц могут обеспечить только вакцинные препараты, эффективность которых превышает действие стандартной вакцины БЦЖ [11]. С точки зрения второго предположения, целесообразно конструировать равные по эффективности БЦЖ вакцинные препараты, механизм действия которых не зависит от влияния микобактерий окружающей среды, например вакцины на основе рекомбинантных белковых конструкций или вирусных векторов [10, 12]. При этом проведение клинических исследований новых вакцинных кандидатов предполагает оценку безопасности и иммуногенной активности вакцинного препарата как у иммунологически «наивных» в отношении туберкулеза индивидуумов, так и у PPD-позитивных (англ. purified protein derivative - лица с положительной туберкулиновой пробой) добровольцев [13].

Результаты исследований последних лет показали, что несостоятельность вакцины БЦЖ в странах Африки и тропических регионах может быть связана с высоким уровнем заболеваемости населения паразитарными инвазиями, приводящими к поляризации иммунного ответа в сторону $\mathrm{T}_{\mathrm{x} 2}$-звена [14-16]. В основе негативного влияния гельминтозов на формирование адекватного специфического поствакцинального иммунного ответа лежит не только изменение иммунологического профиля с доминированием $\mathrm{T}_{\mathrm{x} 2}$-иммунного ответа, но также акти- вация регуляторных Т-клеток ( $\left.\mathrm{T}_{\text {reg }}\right)$, секретирующих трансформирующий фактор роста $\beta$ (TGF $\beta$ ) и интерлейкин 10 (ИЛ 10) - ключевые факторы супрессии иммунного ответа $[17,18]$.

Сравнительный генетический анализ лабораторных вирулентных штаммов микобактерий и клинических изолятов M. tuberculosis позволил обнаружить протяженные RD1-RD16-хромосомные участки (RD - region of differences, области различий), утраченные в процессе длительного культивирования вакцинного штамма БЦЖ. Большинство белков, кодируемых утраченными областями, связано с патогенностью и вирулентностью микобактерий туберкулеза [19]. Наряду с этим белки RD1-области играют исключительно важную роль в процессах формирования протективного иммунитета. К последним, в частности, относятся ранний секреторный белок ESAT-6 (Early Secreted Antigen Target, 9,8 КДа) и два других белка этого семейства - Rv3874 (CFP-10) и Rv0288 (ТВ10.4), которые распознаются на ранней стадии туберкулезной инфекции и способствуют пролиферации лимфоцитов, ответственных за продукцию интерферона $\gamma$ (ИФН- $\gamma)-$ основного фактора протективного иммунитета [20]. Учитывая эти свойства, белки семейства ESAT-6 используют для разработки новых вакцинных кандидатов и высокоспецифичных тест-систем для дифференциальной диагностики БЦЖ-вакцинированных и инфицированных микобактериями лиц [21, 22].

Формирование эффективной защиты против туберкулеза зависит от взаимодействия субпопуляций CD4+ и CD8+ T-клеток [23]. В то же время вакцинация БЦЖ индуцирует преимущественно Т-клетки фенотипа CD4+, что, как принято считать, недостаточно для развития полноценной защиты [24]. Эффективность вакцинного штамма БЦЖ может быть увеличена путем повышения способности индуцировать иммунный ответ за счет усиления выработки CD8+-T-клеток, рестриктированных молекулами главного комплекса гистосовместимости класса I (ГКГ I). Данный подход применяют при разработке рекомбинантных БЦЖ-вакцин, экспрессирующих порообразующие белки-цитолизины [25].

Отсутствие долговременной защиты от туберкулеза I.M. Orme связывает с неспособностью вакцины БЦЖ стимулировать образование долгоживущих CCR7+ центральных - Т-клеток памяти [26]. Эффекторные Т-клетки, обеспечивающие поствакцинальный иммунитет к БЦЖ, расположены в ткани легких, и постепенно, в течение 10-15 лет, исчезают. Феномен генерации и длительного существования центральных клеток памяти в организме лежит в основе всех известных на сегодняшний день методов эффективной вакцинации.

Вариабельность в иммуногенной активности различных штаммов M. bovis БЦЖ, используемых для производства вакцины, может быть связана с фенотипическими отличиями дочерних вакцинных штаммов M. bovis БЦЖ [27, 28]. Транскрипционный анализ генетически более близкого к оригинальному штамму M. bovis БЦЖ штамма Japan и более позднего штамма Pasteur установил отчетливые различия в уровне экспрессии ряда поверхностных белков и иммунодоминатных антигенов [29]. И хотя единого мнения о преимуществах использования одного определенного штамма для разработки вакцин на основе БЦЖ пока не выработано [30], полагают, что ранние вакцинные штаммы БЦЖ (Japan, Sweden, Russia) обладают большей иммуногенной активностью, чем поздние (Pasteur, Danish, Glaxo, Prague). В настоящее 
время на стадии клинических исследований находятся рекомбинантные вакцины VPM1002 и rBCG30, которые были получены на основе БЦЖ-штаммов Prague (VPM1002) и Tice (rBCG30), относящихся к близкородственным поздним вакцинным штаммам БЦЖ.

\section{Направления разработки новых вакцин и схем вакцинации}

Основным направлением повышения эффективности противотуберкулезной вакцинации является разработка новых вакцинных препаратов и эффективных схем вакцинации [31]. Наибольшую поддержку в мире находит стратегия гетерологичной вакцинации (стратегия «primeboost», инициация $\rightarrow$ усиление), в рамках которой для праймирования иммунной системы предлагается использовать вакцину БЦЖ или ее улучшенные аналоги, либо аттенуированные штаммы Mycobacterium tuberculosis, а для последующих бустерных вакцинаций - субъединичные или векторные вакцины, содержащие протективные белки микобактерий [32].

Показано, что первичная вакцинация БЦЖ с последующим введением протективных белков микобактерий эффективно индуцирует Т-клеточный иммунный ответ у мышей, морских свинок, крупного рогатого скота и человека [33]. Предполагают, что данный подход принесет наибольшую пользу в защите населения в регионах с высокой заболеваемостью туберкулезом [34]. В табл. представлены основные вакцинные кандидаты, разделенные по направлениям их разработки (из обзора [31] с модификациями).
Вакцинные кандидаты на основе живых модифицированных штаммов $M$. bovis БЦЖ. Перспективным направлением оптимизации вакцины БЦЖ является расширение путей презентации микобактериальных антигенов в контексте молекул ГКГ І. При этом используют гемолитические свойства белков-цитолизинов, которые обладают способностью образовывать поры в фагосомальной мембране клетки-хозяина, обеспечивая выход антигенов в цитоплазму и праймирование CD8+T лимфоцитов [35]. По этому принципу была сконструирована кандидатная вакцина VPM1002 на основе рекомбинантного штамма БЦЖ, экспрессирующего $N$-концевой домен белка 85В и листериолизин [25]. Кроме того, в данной конструкции из штамма БЦЖ был удален ген уреазы C, который в норме нейтрализует кислотность фагосомы, тем самым созданы оптимальные для активности листериолизина условия окружающей среды. Показан высокий уровень безопасности и эффективности VPM1002 в индукции иммунного ответа с участием CD8+-Tклеток у здоровых взрослых добровольцев. В ближайшем будущем планируется исследование вакцины у детей в рамках клинического исследования ІІа фазы.

Другой подход в разработке вакцин данного направления - усиление иммуногенных свойств штамма БЦЖ путем введения отсутствующих в БЦЖ участков генома RD1-области, кодирующих белки ESAT-6 и CFP-10 [36]. На животных моделях (мыши и морские свинки) показана высокая протективная активность рекомбинантного вакцинного штамма от заражения вирулентным штаммом микобактерий, превышающая действие стан-

Таблица. Вакцинные кандидаты, находящиеся на различных стадиях разработки*

\begin{tabular}{|c|c|c|c|}
\hline & Фаза разработки & Описание & Ссылки \\
\hline \multicolumn{4}{|c|}{ 1. Вакцинные кандидаты на основе живых модифицированных штаммов $M$. bovis БЦЖ } \\
\hline VPM 1002 & $\begin{array}{l}\text { Клиническое } \\
\text { исследование I фазы }\end{array}$ & $\begin{array}{l}\text { Рекомбинантный штамм БЦЖ Prague, экспрессирующий } \\
\text { N-терминальную область антигена 85B и листериолизин; с } \\
\text { делецией гена, кодирующего уреазу }\end{array}$ & 25 \\
\hline rBCG30 & $\begin{array}{l}\text { Клиническое } \\
\text { исследование I фазы }\end{array}$ & $\begin{array}{l}\text { Рекомбинантный штамм БЦЖ Tice, экспрессирующий } \\
\text { антиген 85B }\end{array}$ & 38 \\
\hline Aeras -422 & $\begin{array}{l}\text { Клиническое } \\
\text { исследование I фазы }\end{array}$ & $\begin{array}{l}\text { Рекомбинантный штамм БЦЖ, экспрессирующий } \\
\text { перфринголизин и антигены 85A, 85B, Rv3407 }\end{array}$ & 39 \\
\hline \multicolumn{4}{|c|}{ 2. Вакцинные кандидаты на основе живых аттенуированных штаммов M. tuberculosis } \\
\hline MTBVAC01 $\Delta$ phoP $\Delta$ fad26 (DIM) & \multirow[t]{2}{*}{$\begin{array}{l}\text { Доклинические } \\
\text { исследования }\end{array}$} & $\begin{array}{l}\text { Живая вакцина на основе аттенуированного штамма } M . \text { tuber- } \\
\text { culosis с инактивацией генов phoP и fadD26 }\end{array}$ & 60,61 \\
\hline $\operatorname{MTB}(\Delta$ lysA, $\Delta$ panCD, $\Delta \sec A 2)$ & & $\begin{array}{l}\text { Нерепликативный ауксотрофный по лизину и пантотенату } \\
\text { штамм } M \text {. tuberculosis, аттенуированный за счет удаления гена } \\
\text { secA2 }\end{array}$ & 62 \\
\hline \multicolumn{4}{|c|}{ 3. Вакцинные кандидаты на основе рекомбинантных белков с адъювантом } \\
\hline HybridI + IC31 & $\begin{array}{l}\text { Клиническое } \\
\text { исследование I фазы }\end{array}$ & Белки 85В и ESAT-6 с адъювантом IC31 & 49 \\
\hline HybridI+CAF01 & $\begin{array}{l}\text { Клиническое } \\
\text { исследование I фазы }\end{array}$ & Белки 85В и ESAT-6 с адъювантом CAF01 & 63 \\
\hline Hybrid 56+CAF01 & $\begin{array}{l}\text { Доклинические } \\
\text { исследования }\end{array}$ & Белки 85B, ESAT-6 и Rv2660с с адъювантом CAF01 & 50 \\
\hline M72+AS02 или AS01 & $\begin{array}{l}\text { Клиническое } \\
\text { исследование II фазы }\end{array}$ & Белки Rv1106 и Rv0125 с адъювантом & 64,65 \\
\hline HyVACIV/Aeras-404+IC31 & $\begin{array}{l}\text { Клиническое } \\
\text { исследование I фазы }\end{array}$ & Белки 85В и ТВ10.4 с адъювантом IC31 & 66 \\
\hline \multicolumn{4}{|c|}{ 4. Вакцинные кандидаты на основе рекомбинантных вирусных векторов } \\
\hline MVA85A/Aeras-485 & $\begin{array}{l}\text { Клиническое } \\
\text { исследование II фазы }\end{array}$ & $\begin{array}{l}\text { Модифицированный вирус Vaccinia штамм Ankara, } \\
\text { экспрессирующий антиген 85A }\end{array}$ & 59,67 \\
\hline Ad35/Aeras -402 & $\begin{array}{l}\text { Клиническое } \\
\text { исследование II фазы }\end{array}$ & $\begin{array}{l}\text { Репликативно-дефектный вирусный вектор на основе } \\
\text { аденовируса } 35 \text { серотипа, экспрессирующий антигены 85А, } \\
85 \mathrm{~B}, \text { ТВ10.4 }\end{array}$ & 58 \\
\hline
\end{tabular}

Примечание. * - см. также Ottenhoff T.H.M., Kaufmann S.H.E., 2012. 
дартной вакцины БЦЖ. Однако для получения разрешения регулирующих органов на проведение клинических исследований требуется всесторонняя оценка остаточной вирулентности данной кандидатной вакцины.

Усиление иммуногенности генно-инженерных рекомбинантных вакцин на основе БЦЖ может быть достигнуто путем введения в геном бактерии дополнительных копий генов, кодирующих присутствующие в БЦЖ белки. Таким путем были получены линии штаммов БЦЖ, экспрессирующие в большом количестве секреторный белок Ag85B [37]. В ходе доклинических исследований было показано, что такие штаммы индуцируют более сильный иммунный ответ по сравнению с исходными родительскими штаммами. Результаты клинического исследования вакцинного кандидата rBCG30, экспрессирующего антиген 85B (rBCG30), с участием 30 здоровых добровольцев продемонстрировали хороший профиль безопасности вакцины, однако уровень ее иммуногенной активности оказался ниже ожидаемого [38]. Дальнейшие исследования rBCG30 пока приостановлены.

Используя сочетание двух перечисленных выше подходов, разработали рекомбинантный штамм БЦЖ, экспрессирующий белки $\mathrm{Ag} 85 \mathrm{~A}, \mathrm{Ag} 85 \mathrm{~B}$ и Rv3407 совместно с перфринголизином, гемолитическая активность которого, в отличие от листериолизина, реализуется в более широком диапазоне $\mathrm{pH}$ [39]. В ходе клинического исследования вакцины AERAS-422 у двух добровольцев были зарегистрированы нежелательные явления (реактивация Herpes zoster) тяжелой степени выраженности, что послужило основанием для преждевременного прекращения исследования.

Вакцинные кандидаты на основе живых аттенуированных штаммов M. tuberculosis. Весомым аргументом возможной замены $M$. bovis БЦЖ невирулентным штаммом M. tuberculosis является близость последнего по антигенному составу к инфекционному агенту, что может обеспечить более адекватный, чем у вакцины БЦЖ, спектр и длительность специфичного иммунного ответа, а также открывает возможность проведения повторной иммунизации с использованием антигенов, отсутствующих в БЦЖ.

С помощью делеций определенных генов M. tuberculosis было сконструировано несколько линий аттенуированных ауксотрофных мутантов, зависимых от метаболитов, редко присутствующих в организме хозяина. В целях повышения безопасности и минимизации рисков реверсии к генотипу дикого типа в мутантные штаммы микобактерий вводили дополнительные мутации, приводящие к двойной ауксотрофности. Показан протективный эффект вакцинных кандидатов, содержащих двойные несвязанные друг с другом мутации, приводящие к ауксотрофному фенотипу по двум веществам: лейцину и пантотенату [40], лизину и пантотенату $[41,42]$. Данные штаммы обеспечивали длительный антимикобактериальный иммунный ответ у здоровых и инфицированных вирусом иммунодефицита макак [43].

Еще одним подходом к разработке живых аттенуированных противотуберкулезных вакцин является получение аттенуированного штамма M. tubecrculosis, восстановление вирулентности которого не связано с метаболитами хозяина. Линии микроорганизмов, несущих несколько мутаций, влияющих на метаболические пути микобактерий, связанных с их вирулентностью, могут рассматриваться в качестве перспективных вакцинных кандидатов. На сегодняшний день наиболее изученным оказался прошедший всестороннюю докли- ническую проверку и соответствующий требованиям т.н. Женевского консенсуса вакцинный кандидат MTBVAC: штамм несет 2 стабильные делеции в генах вирулентности phoP и fadD26 и не имеет маркеров устойчивости к антибиотикам [44-46]. В настоящее время определяются условия для проведения клинических исследований данной кандидатной вакцины, которая в перспективе может заменить вакцину БЦЖ.

Также была продемонстрирована эффективность профилактической вакцинации штаммами с мутантным геном secA2, который кодирует компонент системы секреции белков, связанный с вирулентностью, и вызывает усиление апоптоза инфицированных макрофагов путем уменьшения секреции микобактериальной супероксиддисмутазы [47]. Установлен вакцинный потенциал четырехкратных мутантов микобактерий туберкулеза по генам rpf (resuscitation promoting factor) $\triangle A C B D$ и $\triangle A C D E$, кодирующих факторы реактивации роста микобактерий [48]. Необходимо отметить, что вакцинные кандидаты на основе живых аттенуированных вакцинных штаммов M. tuberculosis находятся на стадии доклинических исследований.

Вакцинные кандидаты на основе рекомбинантных белков с адъювантом. Эффективность разработки субъединичных вакцин определяет выбор специфического антигена, обеспечивающего протективный эффект вакцинации. Ранние секреторные белки ESAT-6 и TB10.4 (CFP-7), которые кодируются esx-lhp-опероном в RD1-области генома M. tuberculosis, входят в состав большинства новых вакцинных кандидатов на основе рекомбинантных гибридных белков Hybrid I, Hybrid 56, HyVAC IV/Aeras$404[49,50]$. Помимо белков семейства ESAT-6 в их состав входят 2 секреторных белка трехкомпонентного антигенного комплекса Ag85 - Rv3804 (Ag85A), Rv1886 (Ag85B), а также белки семейства сериновых протеаз МТВ32 [51]. В настоящее время проводятся доклинические исследования белка теплового шока 65 (HSP65), который вызывает преимущественную стимуляцию CD8+ цитотоксических Т лимфоцитов, лизирующих инфицированные макрофаги, неспособные к элиминации микобактерий [52]. Также разрабатывается стратегия т.н. многоступенчатой вакцинации (вакцинный кандидат Hybrid 56), в которой используется комбинация секреторных белков ESAT-6 и Ag85B с белком Rv2660с, активная экспрессия которого показана в латентной фазе инфекции [50].

Важным этапом создания субъединичных вакцин на основе белков M. tuberculosis, имеющих недостаточную иммуногенность, является подбор оптимального адъюванта, способного стимулировать Т-клеточный иммунный ответ. На стадии разработок противотуберкулезных вакцин находится 4 основных адъюванта, относящихся к комбинированным адъювантным системам, состоящим из нескольких веществ с различными функциями и активностью.

- CAF01 (LipoVac) - синтетический микобактериальный иммуномодулятор на основе трихалозы, провоспалительное действие которого направлено на выработку по TLR-независимому пути цитокинов $\mathrm{T}_{\mathrm{xl}}$-типа [53].

- В составе адъюванта IC31 содержится синтетический антимикробный пептид KLKL5KLK, действие которого направлено на усиление взаимодействия антигенпрезентирующих клеток с антигеном, и TLR9 лиганд ODN1a, обладающий иммуностимулирующим действием. Включение IC31 в состав вакцинных кандидатов Hybrid 1 и HyVAC IV сопровождалось формированием выраженного T-клеточного ответа со сме- 
шанным $\mathrm{T}_{\mathrm{x} 1} / \mathrm{T}_{\mathrm{x} 2}$ цитокиновым профилем у привитых новорожденных и взрослых [54].

- AS01 и AS02 - адъювантные системы, содержащие иммуностимуляторы монофосфорил липид А и дериват сапонина QS-21 в липосомальной (AS01) или эмульсионной «масло/вода» (AS02) форме [55].

B обзоре S.A. Moreno-Mendieta и соавт. представлены подробные характеристики новых адъювантов, входящих в состав разрабатываемых противотуберкулезных вакцин [56].

Вакцинные кандидаты на основе рекомбинантных вирусных векторов. Одним из способов, позволяющих повысить иммуногенность микобактериальных антигенов без применения адъювантов, служит использование аттенуированных вирусов или бактерий в качестве вектора для доставки и экспрессии антигена в организме. В настоящее время исследуется протективный потенциал векторов на основе аттенуированных вирусов (аденовирус, вирус осповакцины, вирус гриппа), несущих протективные микобактериальные антигены (ESAT6, $\mathrm{Ag} 85 \mathrm{~A}$, ТВ 10.4). Основным условием применения живых векторных вакцин у людей является надежная аттенуация вакцинного штамма и его безопасность. В то же время репликация рекомбинантного штамма должна сопровождаться выработкой достаточного количества белкавставки для формирования защитного эффекта вакцинации. Перспективным направлением в области разработки противотуберкулезных векторных вакцин считают создание препаратов, ориентированных на формирование иммунного ответа на уровне слизистых оболочек в месте внедрения патогена. Результаты доклинических исследований рекомбинантных гриппозных векторов, экспрессирующих ESAT-6-белок (FLU/ESAT-6) при интраназальном введении, продемонстрировали высокий уровень протективной активности, по ряду показателей превышающей защитное действие вакцины БЦЖ [57].Вакцинные кандидаты на основе живых рекомбинантных аттенуированных аденовирусов различных серотипов, экспрессирующих 3 микобактериальных антигена (85A, 85B и ТВ 10.4) в различных комбинациях, находятся на этапе многоцентровых клинических исследований I/II фазы [58]. Исследования у взрослых БЦЖ-вакцинированных добровольцев из Южной Африки продемонстрировали безопасность аденовирусных векторов и их способность индуцировать образование специфических полифункци- ональных CD4+ T-клеток и высокое содержание CD8+ T-клеток. Среди основных ограничений применения рекомбинантных аденовирусных штаммов можно отметить высокий процент серопозитивных к аденовирусу 5-го серотипа лиц и негативное влияние на эффективность повторной вакцинации выработки противовирусных антител (в титре >1:200) к вектору на основе аденовируса 35-го серотипа при использовании схемы двукратной вакцинации [58].

Наиболее изучена среди векторных кандидатов вакцина на основе модифицированного вируса осповакцины (штамм Анкара), экспрессирущего белок 85А (MVA85A), которая проходит клинические испытания у различных групп населения, включая ВИЧ-инфицированных лиц [59]. Результаты клинических исследований наряду с хорошим уровнем безопасности и иммуногенности вакцины показали усиление под действием вакцинации Т-клеточного ответа у БЦЖ-вакцинированных лиц и у PPD-позитивных индивидуумов, что явилось первым клиническим подтверждением эффективности схемы гетерологичной «prime-boost» вакцинации. Кроме того, поствакцинальный иммунный ответ характеризовался высоким и устойчивым уровнем выработки антигенспецифических ИФН- $\gamma$-секретирующих CD4+ Т-клеток с фенотипом клеток памяти.

В заключении необходимо отметить, что важными требованиями при разработке новых вакцин являются их безопасность, в т.ч. для лиц с иммунодефицитными состояниями, включая ВИЧ-инфицированных людей, а также способность формировать стойкий и длительный протективный иммунитет. При этом противотуберкулезная вакцина в идеале должна предотвращать развитие туберкулеза как у иммунологически «наивных» в отношении туберкулеза лиц, так и у PPD-позитивных индивидуумов, иметь минимум побочных эффектов и быть экономически доступной для широкого использования.

Статья подготовлена по результатам исследования, выполненного в рамках подпрограммы «Туберкулез» Федеральной целевой программы «Предупреждение и борьба с социально значимыми заболеваниями (Государственный контракт Министерства здравоохранения и социального развития Российской Федерации К-32-НИР/114-13 от 31.10.2011 г.).

\section{REFERENCES}

1. Morozov Yu.A., Khadeeva P.V., Mikhailova L.V. Immunoprofilaktika tuberkuleza vaktsinoi BTsZh u detei iz kontakta i iz neustanovlennogo kontakta. Probl. tub. i bol. legkikh. 2005; 1: 29-32.

2. Aksenova V.A., Levi D.T., Fonina E.V., Vundtsettel' N.N. Vaktsinoprofilaktika tuberkuleza: znachenie i problemy. Probl. tub. i bol. legkikh. 2009; 1: 10-16.

3. Klevtsova G.A., Minina N.A., Sanakoeva L.P. Spetsificheskaya fagotsitarnaya reaktsiya leikotsitov u detei, infitsirovannykh i bol'nykh tuberkulezom. Tr. Perm. med. instituta. 1984; 160: 8-11.

4. Sanakoeva L.P. Spetsificheskie izmeneniya fagotsitarnoi aktivnosti leikotsitov krovi u detei posle vaktsinatsii BCG. Probl. tub. i bol. legkikh. 2003; 8: 40-43.5. Russell D.G., Barry C.E., Flynn J.L. Tuberculosis: what we don't know can, and does, hurt us. Science. 2010; 328: 852-856.

5. Russell D.G., Barry C.E., Flynn J.L. Tuberculosis: what we don't know can, and does, hurt us. Science. 2010; 328: $852-856$.
6. WHO. BCG vaccine. WHO position paper. Wkly Epidemiol. Rec. 2004; 79 (4): 27-38.

7. Rodrigues L.C., Pereira S.M., Cunha S.S., Genser B., Ichihara M.Y., de Brito S.C., Hijjar M.A., Dourado I., Cruz A.A., Sant'Anna C., Bierrenbach A.L., Barreto M.L. Effect of BCG revaccination on incidence of tuberculosis in school-aged children in Brazil: the BG-REVAC cluster-randomised trial. Lancet. 2005; 366 (9493): 1290-1295.

8. Black G.F., Dockrell H.M., Crampin A.C., Floyd S., Weir R.E., Bliss L., Sichali L., Mwaungulu L., Kanyongoloka H., Ngwira B., Warndorff D.K., Fine P.E. Patterns and implications of naturally acquired immune responses to environmental and tuberculous mycobacterial antigens in northern Malawi. J. Infect. Dis. 2001; 184 (3): 322-329.

9. Weir R.E., Black G.F., Nazareth B., Nazareth B., Floyd S., Stenson S., Stanley C., Branson K., Sichali L., Chaguluka S.D., Donovan L., Crampin A.C., Fine P.E., Dockrell H.M. The influence of previous 
exposure to environmental mycobacteria on the interferon-gamma response to bacille Calmette-Guerin vaccination in southern England and northern Malawi. Clin. Exp. Immunol. 2006; 146 (3): 390-399.

10. Brandt L., Feino C.J., Weinreich O.A. Weinreich Olsen A., Chilima B., Hirsch P., Appelberg R., Andersen P. Failure of the Mycobacterium bovis BCG vaccine: some species of environmental mycobacteria block multiplication of BCG and induction of protective immunity to tuberculosis. Infect. Immun. 2002; 70: 672-678.

11. Delogu G., Fadda G. The quest for a new vaccine against tuberculosis. J. Infect. Dev. Ctries. 2009; 3 (1): 5-15.

12. Andersen P., Doherty T.M. The success and failure of BCGimplications for a novel tuberculosis vaccine. Nat. Rev. Microbiol. 2005; 3: 656-662.

13. Rowland R., McShane H. Tuberculosis vaccines in clinical trials. Expert. Rev. Vaccines. 2011; 10 (5): 645-658.

14. ResendeCoT., Hirsch C.S., ToossiZ., Dietze R., Ribeiro-RodriguesR. Intestinal helminth co-infection has a negative impact on both anti-Mycobacterium tuberculosis immunity and clinical response to tuberculosis therapy. Clin. Exp. Immunol. 2007; 147: 45-52.

15. Hatherill M., Adams V., Hughes J., De Kock M., Mavakla W., Pienaar B., Mahomed H., Hussey G., Hanekom W.A. The potential impact of helminth infection on trials of novel tuberculosis vaccines. Vaccine. 2009; 27 (35): 4743-4744.

16. Rafi W., Ribeiro-Rodrigues R., Ellner J.J., Salgame P. Coinfectionhelminthes and tuberculosis. Curr. Opin. HIV AIDS. 2012; 7 (3): 239-244.

17. Churina E.G., Novitskii V.V., Urazova O.I. Faktory immunosupressii pri razlichnykh patologiyakh. Byull. sibirskoi meditsiny. 2011; 4: 103-111.

18. Elias D., Britton S., Aseffa A., Engers H., Akuffo H. Poor immunogenicity of BCG in helminth infected population is associated with increased in vitro TGF-beta production. Vaccine. 2008; 26 (31): 3897-3902.

19. Mahairas G.G., Sabo P.J., Hickey M.J., Singh D.C., Stover C.K. Molecular analysis of genetic differences between Mycobacterium bovis BCG and virulent M. bovis. J. Bacteriol. 1996; 178 (5): 12741282.

20. Brodin P., Rosenkrands I., Andersen P., Cole S.T., Brosch R. ESAT- 6 proteins: protective antigens and virulence factors? Trends Microbiol. 2004; 12: 500-508.

21. Guinn K.M., Hickey M.J., Mathur S.K., Zakel K.L., Grotzke J.E., Lewinsohn D.M., Smith S., Sherman D.R. Individual RD1region genes are required for export of ESAT-6/CFP-10 and for virulence of Mycobacterium tuberculosis. Mol. Microbiol. 2004; 51: $359-370$.

22. van Pinxteren L.A., Ravn P., Agger E.M., Pollock J., Andersen P. Diagnosis of tuberculosis based on the two specific antigens ESAT6 and CFP10. Clin. Diagn. Lab. Immunol. 2000; 7: 155-160.

23. Flynn J.L., Chan J. Immunology of tuberculosis. Ann. Rev. Immunol. 2001; 19: 93-129.

24. Flynn J.L. Immunology of tuberculosis and implications in vaccine development. Tuberculosis (Edinb). 2004; 84 (1-2): 93-101.

25. Grode L., Seiler P., Baumann S., Hess J., Brinkmann V., Nasser Eddine A., Mann P., Goosmann C., Bandermann S., Smith D., Bancroft G.J., Reyrat J.M., van Soolingen D., Raupach B., Kaufmann S.H. Increased vaccine efficacy against tuberculosis of recombinant Mycobacterium bovis bacilli Calmette-Guerin mutants that secrete listeriolysin. J. Clin. Invest. 2005; 115: 2472-2479.

26. Orme I.M. The Achilles heel of BCG. Tuberculosis (Edinb). 2010; 90: 329-332.

27. Behr M.A. BCG-different strains, different vaccines? Lancet Infect. Dis. 2002; 2 (2): 86-92.

28. Ritz N., Hanekom W.A., Robins-Browne R., Britton W.J., Curtis N. Influence of BCG vaccine strain on the immune response and protection against tuberculosis. FEMS Microbiol. Rev. 2008; 32 (5): $821-841$.

29. Brosch R., Gordon S.V., Garnier T., Eiglmeier K., Frigui W., Valenti P., Dos Santos S., Duthoy S., Lacroix C., Garcia-Pelayo C., Inwald J.K., Golby P., Garcia J.N., Hewinson R.G., Behr M.A., Quail M.A., Churcher C., Barrell B.G., Parkhill J., Cole S.T. Genome plasticity of BCG and impact on vaccine efficacy. Proc. Natl. Acad. Sci. USA. 2007; 104: 5596-5601.

30. Corbel M.J., Fruth U., Griffiths E., Knezevic I. Report on a WHO consultation on the characterisation of BCG strains. Vaccine. 2004; 22: $2675-2680$.

31. Ottenhoff T.H.M., Kaufmann S.H.E Vaccines against tuberculosis: where we are and where do we need to go. PLoS Pathogens. 2012; 8: 1002607.

32. Radosevic K., Rodriguez A., Lemckert A., Goudsmit J. Heterologous prime-boost vaccinations for poverty-related diseases: advantages and future prospects. Expert Rev. Vaccines. 2009; 8 (5): 577-592.

33. Svenson S., Kallenius G., Pawlowski A., Hamasur B. Towards new tuberculosis vaccines. Hum. Vaccin. 2010; 6 (4): 309-317.

34. Young D., Dye C. The development and impact of tuberculosis vaccines. Cell. 2006; 124 (4): 683-687.

35. Hess J., Miko D., Catic A., Lehmensiek V., Russell D.G., Kaufmann S.H. Mycobacterium bovis bacille Calmette-Guerin strains secreting listeriolysin of Listeria monocytogenes. Proc. Natl. Acad. Sci. USA. 1998; 95 (9): 5299-5304.

36. Pym A.S., Brodin P., Majlessi L., Brosch R., Demangel C., Williams A., Griffiths K.E., Marchal G., Leclerc C., Cole S.T. Recombinant BCG exporting ESAT-6 confers enhanced protection against tuberculosis. Nat Med. 2003; 9 (5): 533-539.

37. Horwitz M.A., Harth G., Dillon B.J., Maslesa-Galic S. Recombinant bacillus calmette-guerin (BCG) vaccines expressing the Mycobacterium tuberculosis 30-kDa major secretory protein induce greater protective immunity against tuberculosis than conventional BCG vaccines in a highly susceptible animal model. Proc. Natl. Acad. Sci. USA. 2000; 97: 13853-13858.

38. Hoft D.F., Blazevic A., Abate G., Hanekom W.A., Kaplan G., Soler J.H., Weichold F., Geiter L., Sadoff J.C., Horwitz M.A. A new recombinant bacille Calmette-Guerin vaccine safely induces significantly enhanced tuberculosis-specific immunity in human volunteers. J. Infect. Dis. 2008; 198: 1491-1501.

39. Sun R., Skeiky Y.A., Izzo A. Dheenadhayalan V., Imam Z., Penn E., Stagliano K., Haddock S., Mueller S., Fulkerson J., Scanga C., Grover A., Derrick S.C., Morris S., Hone D.M., Horwitz M.A., Kaufmann S.H., Sadoff J.C. Novel recombinant BCG expressing perfringolysin $\mathrm{O}$ and the over-expression of key immunodominant antigens; pre-clinical characterization, safety and protection against challenge with Mycobacterium tuberculosis. Vaccine. 2009; 27: 4412-4423.

40. Sampson S.L., Dascher C.C., Sambandamurthy V.K., Russell R.G., Jacobs W.R. Jr., Bloom B.R., Hondalus M.K. Protection elicited by a double leucine and pantothenate auxotroph of Mycobacterium tuberculosis in guinea pigs. Infect. Immun. 2004; 72: 3031-3037.

41. Larsen M.H., Biermann K., Chen B., Hsu T., Sambandamurthy V.K., Lackner A.A., Aye P.P., Didier P., Huang D., Shao L., Wei H., Letvin N.L., Frothingham R., Haynes B.F., Chen Z.W., Jacobs W.R. Jr. Efficacy and safety of live attenuated persistent and rapidly cleared Mycobacterium tuberculosis vaccine candidates in non-human primates. Vaccine. 2009; 27: 4709-4717.

42. Sambandamurthy V.K., Derrick S.C., Jalapathy K.V., Chen B., Russell R.G., Morris S.L., Jacobs W.R. Jr. Long-term protection against tuberculosis following vaccination with a severely attenuated double lysine and pantothenate auxotroph of Mycobacterium tuberculosis. Infect. Immun. 2005; 73 (2): 1196-1203.

43. Sampson S.L., Mansfield K.G., CarvilleA., MageeD.M., Quitugua T., Howerth E.W., Bloom B.R., Hondalus M.K. Extended safety and 
efficacy studies of a live attenuated double leucine and pantothenate auxotroph of Mycobacterium tuberculosis as a vaccine candidate. Vaccine. 2011; 29: 4839-4847.

44. Cardona P.J., Asensio J.G., Arbues A., Otal .I, Lafoz C., Gil O., Caceres N., Ausina V., Gicquel B., Martin C. Extended safety studies of the attenuated live tuberculosis vaccine $\mathrm{SO} 2$ based on phoP mutant. Vaccine. 2009; 27 (18): 2499-2505.

45. Ferrer N.L., Gomez A.B., Soto C.Y. et al. Intracellular replication of attenuated Mycobacterium tuberculosis phoP mutant in the absence of host cell cytotoxicity. Microbes Infect. 2009; 11(1): 115-122.

46. Verreck F.A., Vervenne R.A., Kondova I., van Kralingen K.W., Remarque E.J., Braskamp G., van der Werff N.M., Kersbergen A., Ottenhoff T.H., Heidt P.J., Gilbert S.C., Gicquel B., Hill A.V., Martin C., McShane H., Thomas A.W. MVA.85A boosting of BCG and an attenuated, phoP deficient $M$. tuberculosis vaccine both show protective efficacy against tuberculosis in rhesus macaques. PLoS One. 2009; 4 (4): 5264-5270.

47. Hinchey J., Lee S., Jeon B.Y., Basaraba R.J., Venkataswamy M.M., Chen B., Chan J., Braunstein M., Orme I.M., Derrick S.C., Morris S.L., Jacobs W.R. Jr., Porcelli S.A. Enhanced priming of adaptive immunity by a proapoptotic mutant of Mycobacterium tuberculosis. J. Clin. Invest. 2007; 117 (8): 2279-2288.

48. Kondratieva T., Rubakova E., Kana B.D., Biketov S., Potapov V., Kaprelyants A., Apt A. Mycobacterium tuberculosis attenuated by multiple deletions of $r p f$ genes effectively protects mice against TB infection. Tuberculosis (Edinb). 2011; 91 (3): 219-223.

49. van Dissel J.T., Soonawala D., Joosten S.A., Prins C., Arend S.M., Bang P., Tingskov P.N., Lingnau K., Nouta J., Hoff S.T., Rosenkrands I., Kromann I., Ottenhoff T.H., Doherty T.M., Andersen P.Ag85B-ESAT-6 adjuvanted with IC31 promotes strong and long-lived Mycobacterium tuberculosis specific T cell responses in volunteers with previous BCG vaccination or tuberculosis infection. Vaccine. 2011; 29 (11): 2100-2109.

50. Aagaard C., Hoang T., DietrichJ., Cardona P.J., IzzoA., Dolganov G., Schoolnik G.K., Cassidy J.P., Billeskov R., Andersen P. A multistage tuberculosis vaccine that confers efficient protection before and after exposure. Nat. Med. 2011; 17 (2): 189-194

51. Skeiky Y.A., Lodes M.J., Guderian J.A., Mohamath R., Bement T., Alderson M.R., Reed S.G. Cloning, expression, and immunological evaluation of two putative secreted serine protease antigens of Mycobacterium tuberculosis. Infect. Immun. 1999; 67 (8): 3998-4007.

52. Lima K.M., dos Santos S.A., Rodrigues J.M., Silva C.L. Vaccine adjuvant: it makes the difference. Vaccine. 2004; 22: 2374-2379.

53. Agger E.M., Rosenkrands I., Hansen J., Brahimi K., Vandahl B.S., Aagaard C., Werninghaus K., Kirschning C., Lang R., Christensen D., Theisen M., Follmann F., Andersen P. Cationic liposomes formulated with synthetic mycobacterial cordfactor (CAF01): a versatile adjuvant for vaccines with different immunological requirements. PLoS One. 2008; 3 (9): 3116-3123.

54. Kamath A.T., Rochat A.F., Valenti M.P., Agger E.M., Lingnau K., Andersen P., Lambert P.H., Siegrist C.A. Adult-like anti-mycobacterial $\mathrm{T}$ cell and in vivo dendritic cell responses following neonatal immunization with Ag85B-ESAT-6 in the IC31 adjuvant. PLoS One. 2008; 3 (11): 3683-3689.

55. Leroux-Roels I., Leroux-Roels G., Ofori-Anyinam O., Moris P., De Kock E., Clement F., Dubois M.C., Koutsoukos M., Demoitie M.A., Cohen J., Ballou W.R. Evaluation of the safety and immunogenicity of two antigen concentrations of the Mtb72F/AS02(A)candidate tuberculosis vaccine in purified protein derivative-negative adults. Clin. Vaccine Immunol. 2010; 17 (11): 1763-1771.

56. Moreno-Mendieta S.A., Rocha-Zavaleta L., Rodriguez-Sanoja R. Adjuvants in tuberculosis vaccine development. FEMS Immunol. Med. Microbiol. 2010; 58 (1): 75-84.

57. Stukova M.A., Sereinig S., Zabolotnyh N.V., Ferko B., Kittel C., Romanova J., Vinogradova T.I., Katinger H., Kiselev O.I.,
Egorov A. Vaccine potential of influenza vectors expressing Mycobacterium tuberculosis ESAT-6 protein. Tuberculosis (Edinb). 2006; 86 (3-4): 236-246.

58. Abel B., Tameris M., Mansoor N., Gelderbloem S., Hughes J., Abrahams D., Makhethe L., Erasmus M., de Kock M., van der Merwe L., Hawkridge A., Veldsman A., Hatherill M., Schirru G., Pau M.G., Hendriks J., Weverling G.J., Goudsmit J., Sizemore D., McClain J.B., Goetz M., Gearhart J., Mahomed H., Hussey G.D., Sadoff J.C., Hanekom W.A. The novel tuberculosis vaccine, AERAS-402, induces robust and polyfunctional CD4 and CD8 T cells in adults. Am. J. Respir. Crit. Care Med. 2010; 181: $1407-1417$.

59. Scriba T.J., Tameris M., Mansoor N., Smit E., van der Merwe L., Isaacs F., Keyser A., Moyo S., Brittain N., Lawrie A., Gelderbloem S., Veldsman A., Hatherill M., Hawkridge A., Hill A.V., Hussey G.D., Mahomed H., McShane H., Hanekom W.A. Modified vaccinia Ankara expressing Ag85A, a novel tuberculosis vaccine, is safe in adolescents and children, and induces polyfunctional CD4 T cells. Eur. J. Immunol. 2010; 40: 279-290.

60. Martin C., Williams A., Hernandez-Pando R., Cardona P.J., Gormley E., Bordat Y., Soto C.Y., Clark S.O., Hatch G.J., Aguilar D., Ausina V., Gicquel B.The live Mycobacterium tuberculosis phoP mutant strain is more attenuated than BCG and confers protective immunity against tuberculosis in mice and guinea pigs. Vaccine. 2006; 24: 3408-3419.

61. Larsen M.H., Biermann K., Chen B., Hsu T., Sambandamurthy V.K., Lackner A.A., Aye P.P., Didier P., Huang D., Shao L., Wei H., Letvin N.L., Frothingham R., Haynes B.F., Chen Z.W., Jacobs W.R. Jr. Efficacy and safety of live attenuated persistent and rapidly cleared Mycobacterium tuberculosis vaccine candidates in non-human primates. Vaccine. 2009; 27: 4709-4717.

62. Derrik S.C., Evering T.H., Sambandamurthy V.K., Jalapathy K.V., Hsu T., Chen B., Chen M., Russell R.G., Junqueira-Kipnis A.P., Orme I.M., Porcelli S.A., Jacobs W.R. Jr, Morris S.L. Characterization of the protective $\mathrm{T}$-cell response generated in D4-defident mice by a live attenuated Mycobacterium tuberculosis vaccine. Immunology. 2007; 120 (2): 192-206.

63. Christensen D., Foged C., Rosenkrands I., Lundberg C.V., Andersen P., Agger E.M., Nielsen H.M. CAF01 liposomes as a mucosal vaccine adjuvant: In vitro and in vivo investigations. Int. J. Pharm. 2010; 390 (1): 19-24.

64. Von Eschen K., Morrison R., Braun M., Ofori-Anyinam O., De Kock E., Pavithran P., Koutsoukos M., Moris P., Cain D., Dubois M.C., Cohen J., Ballou W.R.The candidate tuberculosis vaccine Mtb72F/AS02A: tolerability and immunogenicity in humans. Hum. Vaccin. 2009; 5: 475-482.

65. Leroux-Roels I., Forgus S., De Boever F., Clement F., Demoitie M.A., Mettens P., Moris P., Ledent E., Leroux-Roels G., OforiAnyinam O. The M72 Study Group. Improved CD4(+) T cell responses to Mycobacterium tuberculosis in PPD-negative adults by M72/AS01 as compared to the M72/AS02 and Mtb72F/AS02 tuberculosis candidate vaccine formulations: A randomized trial. Vaccine. 2012; 26 (in press).

66. Dietrich J., Aagaard C., Leah R., Olsen A.W., Stryhn A., Doherty T.M., Andersen P. Exchanging ESAT6 with TB10.4 in an Ag85B fusion molecule based tuberculosis subunit vaccine: efficient protection and ESAT6-based sensitive monitoring of vaccine efficacy. J. Immunol. 2005; 174: 6332-6339.

67. McShane H., Pathan A.A., Sander C.R., Keating S.M., Gilbert S.C., Huygen K., Fletcher H.A., Hill A.V. Recombinant modified vaccinia virus Ankara expressing antigen 85A boosts BCG primed and naturally acquired antimycobacterial immunity in humans. Nat. Med. 2004; 10: 1240-1244. 


\section{КОНТАКТНАЯ ИНФОРМАЦИЯ}

Стукова Марина Анатольевна, кандидат медицинских наук, ведущий научный сотрудник лаборатории молекулярной вирусологии и генной инженерии ФГБУ «Научно-исследовательский институт гриппа» МЗ РФ

Адрес: 197376, Санкт-Петербург, ул. Проф. Попова, д. 15/17

Тел.: (812) 499-15-20

E-mail: stukova@influenza.spb.ru

Киселев Олег Иванович, академик РАМН, профессор, директор ФГБУ «Научно-исследовательский институт гриппа» МЗ РФ

Адрес: 197376, Санкт-Петербург, ул. Проф. Попова, д. 15/17

Тел.: (812) 234-60-00

E-mail: office@influenza.spb.ru

Виноградова Татьяна Ивановна, доктор медицинских наук, профессор, ученый секретарь ФГБУ «СанктПетербургский научно-исследовательский институт фтизиопульмонологии» МЗ РФ

Адрес: 191036, Санкт-Петербург, Лиговский пр-т, д. 2-4

Тел.: (812) 579-25-84

E-mail: vinogradova@ spbniif.ru

Заболотных Наталья Вячеславовна, доктор медицинских наук, ведущий научный сотрудник лаборатории экспериментального туберкулеза и новых медицинских технологий ФГБУ «Санкт-Петербургский научно-исследовательский институт фтизиопульмонологии» МЗ РФ

Адрес: 191036, Санкт-Петербург, Лиговский пр-т, д. 2-4

Тел.: (812) 297-86-31

E-mail: zabol-natal@yandex.ru

Яблонский Петр Казимирович, доктор медицинских наук, профессор, директор ФГБУ «Санкт-Петербургский научно-исследовательский институт фтизиопульмонологии» МЗ РФ, профессор медицинского факультета ФГБО ВПО «Санкт-Петербургский государственный университет»

Адрес: 191036, Санкт-Петербург, Лиговский пр-т, д. 2-4

Тел.: (812) 579-25-54

E-mail: spbniif_all@mail.ru

Ерохин Владислав Всеволодович, доктор медицинских наук, профессор, член-корреспондент РАМН, директор ФГБУ «Центральный научно-исследовательский институт туберкулеза» РАМН

Адрес: 107564, Москва, ул. Яузская аллея, д. 2

Тел.: (499) 785-91-36

E-mail: cniit@ramn.ru

Гергерт Владислав Яковлевич, доктор медицинских наук, профессор, руководитель отдела иммунологии ФГБУ «Центральный научно-исследовательский институт туберкулеза» РАМН

Адрес: 107564, Москва, ул. Яузская аллея, д. 2

Тел.: (499) 785-90-72

E-mail: hergert@mail.ru

Anm Александр Соломонович, доктор биологических наук, профессор, заведующий лабораторией иммуногенетики ФГБУ «Центральный научно-исследовательский институт туберкулеза» РАМН

Адрес: 107564, Москва, ул. Яузская аллея, д. 2

Тел.: (499) 785-90-72

Капрельяни Арсений Сумбатович, доктор биологических наук, профессор, заведующий лабораторией стрессов микроорганизмов ФГБУ «Научно-исследовательский институт биохимии им. А.Н. Баха» РАН

Адрес: 125284, Москва, Ленинский пр-т, д. 33

Тел.: (495) 954-40-47

E-mail: inbi@inbi.ras.ru 